\title{
A construção de conceitos sobre a pequenez humana: Astronomia em aulas de Filosofia no Ensino Médio
}

\author{
The construction of human smallness concepts: Astronomy in \\ Philosophy classes in high school \\ Carlos Alexandre do Nascimento ${ }^{1}$; Paulo Sergio Bretones ${ }^{2}$.
}

1 Mestre, Secretária da Educação do Estado de São Paulo, Ribeirão Preto, São Paulo, Brasil - nascimento.adm@gmail.com/ 0000-0003-3087-5249

2 Doutor, Universidade Federal de São Carlos, São Carlos, São Paulo, Brasil - bretones@ufscar.br/ 0000-0002-0623-8277

Palavras-chave: Ensino de astronomia; Ensino de filosofia; Interdisciplinaridade; Proposta de ensino; Condição humana.
RESUMO: Este artigo apresenta o resultado de uma pesquisa na qual se analisou de que maneira o uso de conteúdos de Astronomia, trabalhados em aulas de Filosofia podem auxiliar na análise crítica dos estudantes do Ensino Médio sobre a existência, com enfoque na pequenez humana. Em uma abordagem interdisciplinar, tratou-se da relação entre Astronomia e Filosofia como áreas afins para uma reflexão existencialista. A abordagem culminou na criação de conceitos sobre a condição humana na Terra e no Cosmo. A metodologia utilizada utilizou questionários, relatos verbais e escritos e anotações do pesquisador-professor. A análise do itinerário da criação de conceitos pelos dos alunos validou a proposta mostrando que a intangibilidade da Filosofia foi assimilada por meio de conteúdos de Astronomia. As reflexões sobre a existência humana caminharam para a análise de nossa condição de pequenez diante da realidade terrena e cósmica.

ABSTRACT: This article presents the results of a research that analyzed how the use of Astronomy contents, worked in classes of Philosophy can help in the critical analysis of the students of high school on the existence, with focus on human smallness. In an interdisciplinary approach, the relationship between Astronomy and Philosophy was treated as related areas for an existentialist reflection. The approach culminated in the creation of concepts about the human condition on Earth and the Cosmos. The methodology used questionnaires, verbal and written reports and notes of the teacher researcher. The analysis of the itinerary of concept creation by the students validated the proposal showing that the intangibility of Philosophy was assimilated through Astronomy contents. The reflections on human existence went to the analysis of our condition of smallness before the earthly and cosmic reality. 


\title{
INTRODUÇÃO
}

$\mathrm{O}$ artigo apresenta uma pesquisa que buscou encontrar caminhos de como trabalhar conteúdos de Filosofia e Astronomia para que o processo de ensino e aprendizagem dos conteúdos destas áreas do saber sejam mais adequados à realidade dos alunos do Ensino Médio.

Mediante este pano de fundo alguns questionamentos germinaram: diante das abordagens Histórica e Temática, qual o modelo a escolher? Diante do objetivo de ensino da Filosofia - em cultivar a formação cidadã - como estes conteúdos podem contribuir? Como a Astronomia pode contribuir para que este processo aconteça de forma eficiente?

Deleuze e Guattari (1992) são defensores que o ensino de Filosofia seja tal como uma oficina de conceitos; uma atividade intelectual sem início nem fim, não paralisante; uma averiguação que busca reflexões constantes e não respostas imediatas. Para Gallo (2006):

\begin{abstract}
Em suma, podemos dizer que ensinar Filosofia é um exercício de apelo à diversidade, ao perspectivismo; é um exercício de acesso a questões fundamentais para a existência humana; é um exercício de abertura ao risco, de busca da criatividade, de um pensamento sempre fresco; é um exercício da pergunta e da desconfiança da resposta fácil. Quem não estiver disposto a tais exercícios, dificilmente encontrará prazer e êxito nesta aventura que é ensinar Filosofia, aprender Filosofia. (GALLO, 2006, p. 20).
\end{abstract}

Assim, a Filosofia está posta para criar as possibilidades de desenvolvimento de uma visão mais crítica do aluno. Nielsen Neto (1986) avigora esta afirmação, ao referir que "não se formará o estudante simplesmente para ingressar no mercado de trabalho, mas para poder participar e contribuir efetivamente para a vida política".

O saber filosófico se apresenta complexo o que faz gerar determinadas aporias no andamento da organização de seus conteúdos e arquitetar junto aos alunos do Ensino Médio. A Filosofia tem como um dos seus objetivos apresentar os instrumentos que o estudante precisa para a apreensão e uma ação mais crítica no seu contexto social (BARBOSA, 2008). Aranha e Martins (2009) robustecem este pensar, ao citarem que a Filosofia é necessária por instigar a um estranhamento, buscando uma dimensão da realidade além das necessidades imediatas nas quais o aluno se encontra mergulhado. Assim, o discente se torna capaz de superar a situação dada, ao mesmo tempo em que repensa as ações que o pensamento inicialmente desencadeia, abrindo-se assim a mudanças.

A Filosofia tem o papel criar a "Ágora” da reflexão, como ocorre em outras áreas, acolhendo o tirocínio de um ajuizar durável. "A Filosofia é um modo de pensar, é uma postura diante do mundo. A Filosofia não é um conjunto de conhecimentos prontos, um sistema acabado, fechado em si mesmo" (ARANHA; MARTINS, 1998, p. 77). O estudante ante o estudo de Filosofia, auxiliado pela Astronomia, tem a probabilidade de se alocar ante 
os fatos, buscando pensar sobre os episódios a partir de certos arranjos teóricos, indo além da aparência presente em seu entorno.

Na Proposta Curricular do Estado de São Paulo, o alvo de inserir o estudante na natureza subjetiva das feições alegóricas é retomado para acaudilhar o currículo de Filosofia. Contudo, ao se debruçar o olhar sobre o conteúdo do currículo do Estado de São Paulo, podem ser identificadas reflexões às vezes pragmáticas. De tal modo, a iniciação da Astronomia poderá nos dar a extensão que falta no currículo, dimensão à qual indica que o ser humano pertence a uma estrutura maior chamada Universo, consistir em uma posição terrena apenas um "pálido ponto azul”, como chamaria Carl Sagan (1996), na vastidão do silente e surpreendente espaço. Isso seria possível, se em aulas sobre tal conteúdo fossem feitas ponderações sobre o mote da humanidade, nossa posição e função no Universo.

Fernandes (2010, p. 106) completa: "Vendo que o ensino de Astronomia tem uma grande receptividade pelos estudantes em relação a essas questões existenciais, podem-se trabalhar vários assuntos correlacionados".

Tendo em vista a Astronomia, sabe-se que, desde os primórdios e durante o desenvolvimento da História do Pensamento Ocidental são vários aqueles que trabalharam a temática, entre eles: Ptolomeu, Aristóteles, Tycho Brahe, Johannes Kepler, Nicolau Copérnico e Galileu Galilei, além de muitos outros, com indagações básicas da Filosofia, como: Quem somos nós? De onde viemos? Qual a origem de todas as coisas? Tais pontos estão coevos no pensamento do ser humano há muito tempo, nos levando a pensar o homem como um "ser cósmico".

Neste artifício o homem pode sair de si, do Planeta, da Galáxia, para procurar respostas sobre ele mesmo.

Tem-se ainda a Astronomia com a probabilidade de cooperar para o exercício da ciência e da arte. Além de ciência, ela propicia um tirocínio estético, ou seja, a ocasião de entrar na beleza proporcionada pela natureza cósmica, admirá-la e ao mesmo tempo permitir o procedimento de inquirição como, por exemplo: qual seria o nosso papel nesta vastidão? A sugestão, além do ensino desta ciência, como a Cosmologia, é a de ser um utensílio para admissão de conteúdos filosóficos e a de pensar na probabilidade do ensino interdisciplinar.

Nielsen Neto (1986) robustece que a fortuna da Filosofia está em sua multiplicidade. "O contato com a pluralidade de abordagens de um mesmo problema, por exemplo, dará ao estudante uma visão muito mais rica do seu próprio mundo.” (NIELSEN NETO, 1986, p. 116). De tal modo, a probabilidade de trabalhar a interdisciplinaridade é própria da Filosofia, o que abona, neste trabalho, tal esperança em relação à Astronomia.

Desta forma,

[...] o foco não é a construção (ou "aquisição", como se costuma pressupor nas abordagens convencionais) de conhecimento específicos em Astronomia, desde as 
perspectivas disciplinar e tecnocrata-progressista convencionais. Da forma que entendemos uma abordagem [...] para ser usada como incentivo àquilo que, de fato, carecemos atualmente, que são o sentir, o pensar e o agir solidários, cooperativos, éticos [...] decorrentes do aprofundamento de um processo comprometido de autoconhecimento. (JAFELICE, 2006, apud MEDEIROS, 2010, p. 166).

Conjectura-se deste modo que a interdisciplinaridade pode ocorrer envolvendo um tema técnico-científico em uma disciplina que permita o aporte teórico para a formação do sujeito crítico, que também pode ser praticada no ensino em ciências.

A Astronomia tem origens comuns com a Filosofia, se for considerada como ciência dos mitos que os antigos tinham dos céus - pois os astros eram como deuses - e que a Filosofia tem sua constituição precisamente na busca da racionalização de tais fatos, episódios e acontecimentos outrora elucidados pela mitologia Grega. Além disso, a Astronomia, como várias outras ciências, se não todas, brotaram da Filosofia, pois é nela que o Homem dá os primários passos de um pensamento racional.

Deve-se levar em conta ainda que a Astronomia é uma das ciências iniciais dominadas pelo homem. Portanto, a compreensão e sua análise conceitual colaboraria para um desenvolvimento mais completo dos alunos. Andar por relatos em observações arqueológicas, por exemplo, pode-se verificar que nos primórdios do desenvolvimento da humanidade, o céu já era retratado, admirado com assombro e já se arriscava a estudar seus enigmas.

\section{ASTRONOMIA E FILOSOFIA: UM DIÁLOGO POSSÍVEL?}

Considerando a probabilidade de se trabalhar conteúdos de Astronomia em aulas de Filosofia, podem-se encontrar dados das duas áreas, os quais, se trabalhados em sala de aula e articulados por uma proposta de atividades, permitiriam ponderações por parte dos educandos sobre o papel do Ser Humano no Universo.

Enquanto ciência, de forma geral, a Astronomia não tem limites, ou seja, ela se volta à procura constante e, tal qual a razão humana, se apresenta ilimitada. Para corroborar com esta afirmação, indiquemos um dos axiomas da Filosofia ocidental, conferida ao filósofo Sócrates: "O último passo da razão é de reconhecer que existem infinitas coisas que a supera" (REALE e ANTISERI, 1990, p. 8).

Esta ciência dos astros estuda desde os menores astros do Sistema Solar até as mais distantes galáxias. Ela tenta responder às perguntas fundamentais: De onde viemos? Estamos sós? Onde estamos? Para onde vamos? Voltando-se ao passado, nota-se que o homem sempre olhou para o céu com curiosidade e fazendo ciência.

Aranha e Martins (2009, p. 293) corroboram essa questão, ao mencionar:

A Filosofia surgiu na Grécia por volta dos séculos VII e VI a.C., mais propriamente nas colônias gregas da Jônia e da Magna Grécia. Conhecida como Filosofia présocrática, representou um esforço de racionalização para desvincular-se do pensamento mítico. Caracterizou-se pelas questões Cosmológicas, por especular a 
respeito da natureza do mundo físico e da sua origem (a arkhé), o princípio de todas as coisas.

Ainda no que se refere à literatura da área de educação em Astronomia, em diversos artigos publicados referente a levantamentos e análises da produção ou mesmo do tipo estado da arte, não foram localizadas produções referentes à relação entre Filosofia e Astronomia, como: Bretones e Megid Neto (2005), que analisaram as teses e dissertações defendidas no Brasil; Bussi e Bretones (2013) e Fernandes e Nardi (2015) sobre os trabalhos em educação em astronomia nos Encontros Nacionais de Ensino de Ciências (ENPECs), Ortelan e Bretones (2012) sobre trabalhos de educação em astronomia apresentados nas reuniões anuais da Sociedade Astronômica Brasileira, (SAB), além de Marrone Júnior e Trevisan (2009) e Iachel e Nardi (2010) sobre os trabalhos de astronomia em periódicos de ensino de física. No âmbito internacional também foram publicados estudos sobre trabalhos apresentados em eventos de educação da União Astronômica Internacional (IAU) por Bretones e Megid Neto (2011), artigos publicados na Revista Latino-Americana de Educação em Astronomia (RELEA) por Bretones, Jafelice e Horvath (2016) e também o levantamento feito por Lelliott e Rollnick (2010) ao analisarem artigos sobre educação em astronomia publicados em revistas internacionais de educação em ciências.

Sendo assim, considera-se original tal abordagem e, portanto, fazem-se necessários desenvolvimento e análise de tais metodologias junto aos alunos.

Visando um possível diálogo da Astronomia com a Filosofia, podem ser abordados conteúdos sobre distâncias e tamanhos dos astros. Neste primeiro momento, espera-se uma admiração inicial que atraia o aluno ao conteúdo, pois olhar para o céu, verificando sua dimensão em relação à pequenez do nosso planeta e da humanidade, traz em si certa angústia e espanto, que serão utilizados como moções motivadoras para o estudo da Filosofia e da própria Astronomia. Neste processo interdisciplinar, na tentativa de responder às perguntas: De onde viemos? Estamos sós? Onde estamos e Para onde vamos?, é possível abordar contribuições da Filosofia.

O plano proposto foi realizado em uma Escola Estadual, localizada na região de Ribeirão Preto, no estado de São Paulo, numa classe de $1^{\circ}$ ano do Ensino Médio com um total 35 alunos. A sugestão pedagógica para a abordagem do conteúdo com os alunos é descrita abaixo. Considerando-se 7 aulas duplas ou 14 aulas simples, todas tiveram como atividade final o desenvolvimento de um texto sobre a problemática apresentada e/ou um relato escrito pelos alunos.

\section{UMA PROPOSTA DE METODOLOGIA}

No que se refere ao ensino de Filosofia, uma proposta de metodologia para sala de aula pode levar em conta o que é proposto pelos Parâmetros Curriculares Nacionais (PCN) 
(BRASIL, 1999), que apresentam competências e habilidades a serem desenvolvidas Representação e Comunicação (Ler textos filosóficos de modo significativo; Ler, de modo filosófico, textos de diferentes estruturas e registros; Elaborar por escrito o que foi apropriado de modo reflexivo; Debater, tomando uma posição, defendendo-a argumentativamente e mudando de posição perante argumentos mais consistentes); Investigação e compreensão (Articular conhecimentos filosóficos e diferentes conteúdos e modos discursivos nas Ciências Naturais e Humanas, nas Artes e em outras produções culturais) e Contextualização sociocultural (Contextualizar conhecimentos filosóficos, tanto no plano de sua origem específica, quanto em outros planos: o pessoal-biográfico, o entorno sócio-político, histórico e cultural e o horizonte da sociedade científico-tecnológica).

Além disso, Souza (1995) contribui igualmente com a indicação de métodos didático-pedagógicos possíveis, sendo eles: Exposição (Apresentação oral do docente sobre a temática), Interrogação (Uso de perguntas (método escolástico)), Exposição dialogada (Processo dialético com perguntas e respostas (método socrático)); Leitura e análise de textos (Leitura de trechos da obra original); Análise linguística (Análise de expressões e etimologia das palavras) e Estudo dirigido (O aluno direciona seus estudos considerando seu interesse).

Considerando estas orientações o trabalho foi realizado de tal forma que se pensou em como trazer conteúdos de Astronomia para as aulas de Filosofia e provocar reflexões nos alunos, com vistas à argumentação e a uma visão crítica do discente, considerando o indicado pelos PCN e a metodologia proposta por de Souza (1995).

Num conjunto de sete aulas, foi proposto, de início, que os alunos olhassem para o céu, contemplassem a noite, observando a natureza e indagando-se sobre sua própria existência. Após isto, foi proposta a apresentação de vídeos criados a partir dos textos de Carl Sagan e de Mário Sérgio Cortella. Posteriormente, houve uma aula expositiva geral e descritiva sobre conteúdos de Astronomia. Nas aulas seguintes, foram feitas leituras e discussões, utilizando-se fragmentos das obras dos filósofos Pascal, Heidegger, Sartre e Arendt.

\section{METODOLOGIA DE PESQUISA}

Como problema de pesquisa e tema deste artigo, procurou-se investigar de que forma o uso de reflexões sobre o Universo no contexto da Filosofia do Ensino Médio pode auxiliar para a criação de uma visão crítica sobre a própria existência pelo aluno?

Visando a proposta, aplicação e análise de uma metodologia de ensino junto a alunos cursando disciplina de Filosofia de Ensino Médio, a metodologia utilizada foi qualitativa, com um estudo de caso para analisar as informações coletadas. 
Os recursos usados foram: aulas expositivas com textos, vídeos, projeções de imagens e outros recursos. Importante ressaltar o uso das mídias eletrônicas para também atrair a atenção dos jovens de forma didática considerando a cultura digital na qual estão inseridos. Além do material disponibilizado pelo Estado de São Paulo, foram aprofundados os estudos utilizando as referências citadas no Caderno do Aluno. Depois da aplicação dos conteúdos, foi utilizada a análise de discurso com as mesmas questões iniciais propostas, para verificar qual foi o desenvolvimento dos alunos, categorizando suas falas, a fim de colher um panorama qualitativo do conteúdo apresentado e apreendido pelos discentes. Uma auladebate, para que os alunos pudessem expor suas opiniões aos demais sobre o conteúdo apresentado, obtendo dados a partir de gravação desses relatos, foi considerada uma ferramenta útil como análise de conteúdo.

Para responder às questões e chegar aos objetivos do trabalho, recorreu-se a várias fontes de dados: questionários, relatos verbais e escritos e anotações do pesquisador. Cada uma das fontes e as formas com que foram estudadas são apresentadas a seguir. Vale destacar que a pesquisa passou por todos os procedimentos legais e éticos necessários, obtendo a autorização do CEP/CONEP (Comissão de Ética e Pesquisa do Conselho Nacional de Saúde) $\mathrm{n}^{\mathrm{o}}$ 08/04/2016, devidamente acompanhado pelo Comitê de Ética da Universidade de São Carlos - SP.

Inicialmente foi aplicado um Questionário Inicial, objetivando colher informações prévias dos alunos sobre seus conhecimentos e percepções. Durante as aulas, foram realizados, vários debates. Com maior ou menor intensidade, a cada aula era sugerida uma discussão a respeito de um tema. No final, elaborava-se um relato escrito, guiado pelas questões apresentadas no plano de aula. Durante o processo foram anotadas algumas falas e ações dos alunos juntamente com a gravação de áudio e vídeos, para posterior verificação na avaliação dos dados. Como o pesquisador/professor estava totalmente inserido na condução das aulas e debates, o tempo para anotação foi pequeno, por isso foi feito uso de recursos tecnológicos para tais registros. Recorreu-se igualmente à memória, pois eventuais discussões e relatos extra aula também ocorreram. Ao final, foi aplicado um Questionário Final, para reproduzir e verificar a evolução conceitual de conteúdos de Astronomia e principalmente do discurso sobre o próprio ser.

Para a análise de dados utilizou-se a Análise de Conteúdo (BARDIN, 2011) Conforme Bardin (2011, p. 126): “As diferentes fases da análise de conteúdo, tal como o inquérito sociológico ou a experimentação, organizam-se em torno de três polos cronológicos: 1) a pré-análise; 2) a exploração; 3) o tratamento dos resultados, a inferência e a interpretação". 
Para a aplicação e análise das aulas, optou-se pela sequência didática proposta por Gallo (2016), que coloca a Filosofia como aquela que possibilita a geração de conceitos.

Deleuze e Guattari (2013) entendem o processo filosófico como aquele que leva à criação de um conceito. A partir de bases teóricas, o aluno é levado a um construtivismo filosófico. Gallo (2006) corrobora essa ideia e acrescenta que a "oficina de conceitos" passa por quatro etapas, que apresentamos a seguir.

A sensibilização é a etapa na qual se pode dirigir a atenção dos alunos para o tema do trabalho de pesquisa. Inicia-se esta etapa observando o céu, propiciando a oportunidade de sensibilização por parte dos alunos, levantando indagações de forma a perceberem que fazem parte deste todo gigantesco que é o Cosmos e refletirem sobre a sua posição nesse contexto.

A problematização, por sua vez, é a etapa que instiga os alunos a transformarem a temática num problema para pesquisa e reflexão. Nos vídeos, conforme apresentado a seguir, foi trabalhada esta etapa e o tema foi problematizado.

A investigação é a fase em que, como docentes, apresentamos instrumentais para que os alunos encontrem a resposta para o problema. Neste momento foram trabalhados os conteúdos de Astronomia e de Filosofia.

Finalmente, a conceituação objetiva que o aluno crie e recrie o seu conceito. No nosso caso, sobre a pequenez humana e sua relação com o Universo.

Conforme o autor pode-se fazer dos conceitos criados uma "arma de luta". O aluno, ao criar conceitos sobre si, tem condições de "lutar" com a realidade, ser mais reflexivo e agente transformador da realidade. Não é possível iniciar uma batalha sem conhecer as próprias habilidades e refletir se há condições de enfrentar o opositor. Assim, pensar a sua existência possibilita uma interpretação mais abrangente da realidade do outro, da sociedade, da situação social, situação política etc.

\section{RESULTADOS E DISCUSSÃO}

A sequência de aulas é descrita a seguir e posteriormente feita uma análise considerando o caminhar de três alunos

\section{$1^{a}$ AULA: QUESTIONÁRIO INICIAL}

Procedimentos: Avaliação dos alunos pelo Questionário Inicial, com o objetivo de colher informações sobre quais astros os alunos conheciam, o que conheciam sobre o Universo e chegar às questões filosóficas (ANEXO A).

\section{2a AULA: OBSERVAÇÃO DO CÉU}

Procedimentos: Iniciou-se a aula com a observação do céu a olho nu, sem instrumentos e colocando para os alunos ouvirem a música "Tendo a Lua" (OS PARALAMAS DO SUCESSO, 1991). A proposta era instigar os alunos com 
questionamentos como “o que sentem ao olhar para o céu?", "quais indagações vêm à mente?".

\section{$3^{a}$ AULA: APRESENTAÇÃO DE VÍDEOS E TEXTOS}

Procedimentos: Apresentação dos vídeos "Você sabe com quem está falando" 1 (CORTElLA, 2015) e "Pálido Ponto Azul" 2 (SAGAN, 1996). Pediu-se aos alunos que fizessem comentários em forma de debate e, na sequência, foram entregues os textos sobre os vídeos. Sugeriu-se que esses textos fossem lidos antes da aula seguinte.

\section{4a AULA: CONTEÚdOS DE ASTRONOMIA}

Procedimentos: Aula expositiva geral e descritiva sobre os conteúdos sobre História da Astronomia, instrumentos, astronáutica, Sistema Solar, estrelas, galáxias, cosmologia, distâncias no Universo e tamanho dos astros. Ao final, foram promovidos debates, com a seguinte questão inicial, que foi também objeto de produção escrita: Sobre as aulas de Astronomia, o que mais lhe chamou atenção? Quais os sentimentos e pensamentos que lhe vieram à mente?

\section{E $6{ }^{a}$ AULAS: LEITURA DE TEXTOS FILOSÓFICOS}

Procedimentos: Leituras e debates sobre textos dos filósofos Blaise Pascal (PASCAL, 1973), Martin Heidegger (HEIDEGGER, 2005), Jean-Paul Sartre (SARTRE, 2015), Hannah Arendt (ARENDT, 2015). Sugestão de leitura para a aula seguinte.

\section{7 aULA: QUESTIONÁRIO FINAL}

Procedimentos: Avaliação dos alunos pelo Questionário Final com o objetivo de avaliar evolução conceitual dos alunos sobre o conteúdo e questões filosóficas (ANEXO A).

Inicialmente, com o objetivo de analisar a aquisição de conhecimentos dos alunos, foram usadas as etapas propostas por Gallo (2006) no que considera uma definição deleuzoguattariana de filosofia como atividade de criação de conceitos para buscar estabelecer os quatro passos didáticos no trabalho com essa disciplina: sensibilização, problematização, investigação, conceituação.

Para isto, apresentamos aqui a trajetória de três alunos (A1, A6 e A9), ocorrida durante a sequência de aulas, apresentadas no Quadro 1 e analisados a seguir.

\footnotetext{
${ }^{1}$ Disponível em: $<$ https://www.youtube.com/watch?v=P3NpHryB-fQ $>$. Acesso em: 1 jan. 2014.

${ }^{2}$ Disponível em: <https://www.youtube.com/watch?v=4_tiv9v964k>. Acesso em: 1 jan. 2014
} 
Quadro 1 - Síntese da trajetória textual de três alunos, utilizando as etapas de sensibilização, problematização, investigação e conceituação.

\begin{tabular}{|c|c|c|c|c|}
\hline Aluno & Sensibilização & Problematizaçāo & Investigaçào & Conceituagão \\
\hline A1 & $\begin{array}{l}\text { Senti pelos povos } \\
\text { antigos gratidio }\end{array}$ & $\begin{array}{l}\text { Astronomia e Filosofia } \\
\text { possuem grande relaçá [...] } \\
\text { A Astronomia observa [...] } \\
\text { realiza descobertas e formula } \\
\text { teorias [..] na Filosofia estas } \\
\text { tecrias slo aprofundadas [...] } \\
\text { faz reflexlo sobre as ideias } \\
\text { [...] de forma lógica e critica }\end{array}$ & 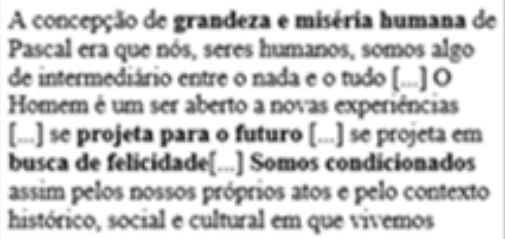 & $\begin{array}{l}\text { O ser humano é uma espécie } \\
\text { entre milhares [...] está numa } \\
\text { estrela em millodes [...] uma } \\
\text { galixia em bilhdes [...] poretm } \\
\text { somos grandes pela nossa } \\
\text { inteligéncia e pequenos, se } \\
\text { comparados ao Universo }\end{array}$ \\
\hline A6 & $\begin{array}{l}\text { Ê incrivel e ao mesmo } \\
\text { tempo assustador } \\
\text { pensar quanto o } \\
\text { universo é grande }\end{array}$ & $\begin{array}{l}\text { Graças a Filosofia e suas } \\
\text { observaçles temos amplo } \\
\text { conhecimento da Astronomia } \\
\text { [...] A Astronomia e a } \\
\text { Filosofia trabalbam juntas } \\
\text { para pensar o mundo }\end{array}$ & 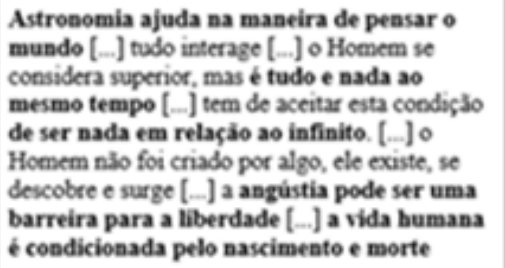 & $\begin{array}{l}\text { O lugar do Homem é confuso, } \\
\text { pois em relaçlo ao todo do } \\
\text { universo somos nada, mas o } \\
\text { fato de podermos observà-lo o } \\
\text { faz existir e se nilo é observado } \\
\text { "nlilo" existe para nós. Entllo } \\
\text { somos parte central disso tudo, } \\
\text { pois o trazemos à existência }\end{array}$ \\
\hline A9 & $\begin{array}{l}\text { Me chamou a atenclo o } \\
\text { fato do planeta ser } \\
\text { menor do que eu } \\
\text { imaginava [..] que } \\
\text { sejamos menores ainda }\end{array}$ & $\begin{array}{l}\text { Slo campos de estudo com a } \\
\text { mesma origem e procuram } \\
\text { questöes da existêscia } \\
\text { humana }\end{array}$ & $\begin{array}{l}\text { O ser bumano é pequeno e ao mesmo tempo o } \\
\text { quanto é grande, considerando que cria coisas } \\
\text { incriveis [...] Nós somos um ser para morte, } \\
\text { enquanto vivemos somos um ser no mundo [...] } \\
\text { um humanismo existencialista }\end{array}$ & $\begin{array}{l}\text { A Terra de imensa comparada ao } \\
\text { nosso tamanho, mas se torna } \\
\text { pequena ao lado do Sol e do } \\
\text { resto do Universo. Assim } \\
\text { somos nós, pequenos e } \\
\text { grandes }\end{array}$ \\
\hline
\end{tabular}

Fonte: Autores (2017).

O Aluno 1 inicia a sensibilização com o seguinte relato: "Senti pelos povos antigos gratidão". Na etapa de problematização verifica-se: "A Astronomia e a Filosofia possuem grande relação [...] A Astronomia observa [...] realiza descobertas e formula teorias [...] na Filosofia estas teorias são aprofundadas [...] faz reflexão sobre as ideias [...] de forma lógica e crítica. Na etapa de investigação retoma os questionamentos levantados na aula de na Astronomia, sobre a gratidão aos povos antigos para o avanço da ciência, que a Astronomia contribuiu para a evolução do conhecimento; todos são temas citados por ele. Na Filosofia, ao trabalhar com os filósofos, ele cita Pascal, para quem o Homem é "nada em relação ao infinito e tudo em relação ao nada; ponto insignificante na natureza [...] grande pela racionalidade [...] Dignidade está na razão humana”. Em Heidegger, reflete sobre o conceito de ser-para-morte como o fim da vida. Em Sartre, considera o Homem como legislador, temos a escolha, a liberdade, porém esta liberdade pode trazer angústia. Arendt traz nos seus escritos o conceito de que a vida é trabalho, obra e ação. Na etapa de conceituação, o aluno descreve "o ser humano é uma espécie entre milhares [...] está numa estrela em milhões [...] numa galáxia em bilhões [...], porém somos grandes pela nossa inteligência e pequenos se comparados ao Universo".

O Aluno 6 no mesmo percurso de sensibilização deixa claro seu espanto ao mencionar como "é incrível e ao mesmo tempo assustador pensar o quanto é grande o universo". Na problematização ele menciona "graças à Filosofia e suas observações temos amplo conhecimento da Astronomia", fazendo alusão aos filósofos da natureza que foram um dos primeiros a observar racionalmente o Cosmos. Além disso, complementa: “A Astronomia 
e a Filosofia trabalham juntas para pensar o mundo". Na fase de investigação menciona que a Astronomia "ajuda na maneira de pensar o mundo [...] tudo interage [...]. Também apresentou interesse pela Astronomia na fala: "fiquei interessado pela Astronomia, pois perguntas foram respondidas e outras formadas em mim". Na Filosofia, de forma resumida, trabalha também os conceitos de grandeza e pequenez do Homem, considerando a teoria de Pascal. Cita ainda "o Homem se considera superior", como mencionam Cortella (2015) e Sagan (1996) nos seus textos. E continua: "mas é tudo e nada ao mesmo tempo [...] tem de aceitar esta condição de ser nada em relação ao infinito". Em Heidegger relata o conceito de que o Homem é o serpara-morte, porém pensa a morte como um novo estado, o máximo da pessoa, numa visão de que ter consciência da morte permite o Homem viver o máximo de sua vida. Em Sartre, menciona que "o Homem não foi criado por algo, ele existe, se descobre e surge [...] a angústia pode ser uma barreira para a liberdade" e acrescenta que o Homem é aquilo que se projeta. Em Arendt, ele destaca que a condição humana tem três elementos fundamentais: o trabalho (biológico); obra (o fazer) e a ação (conviver em sociedade). Menciona ainda que "a vida humana é condicionada pelo nascimento e morte", mas pode ser eternizada por nossas obras.

$\mathrm{Na}$ conceituação temos o relato de que "o lugar do Homem é confuso, pois em relação ao todo do universo somos nada, mas o fato de podermos observá-lo o faz existir e se não é observado "não" existe para nós. Então somos parte central disso tudo, pois o trazemos à existência".

O Aluno 9 observa na sensibilização que "me chamou a atenção o fato do planeta ser menor do que eu imaginava, fazendo que sejamos menores ainda”. Na problematização, ao comparar a Astronomia e a Filosofia relata que "são campos de estudo com a mesma origem e procuram questões da existência humana". Na investigação sobre o universo destaca a enormidade já citada na fase de sensibilização. Na Filosofia relata a grandeza e a miséria do Homem. Em Heidegger, a angústia da vida e da morte. Em Sartre, destaca que o filósofo desenvolve "um humanismo existencialista" se referindo, segundo ele, que as coisas existem para nós observarmos. Sobre este mesmo pensador relata que a angústia surge quando tomamos consciência da liberdade. Na fase de conceituação menciona que "a Terra é imensa comparada ao nosso tamanho, mas se torna pequena ao lado do Sol e do resto do Universo (Sagan). Assim somos nós pequenos e grandes”.

Vale ressaltar que as falas dos discentes estão embebidas de todos os conteúdos trabalhados, os vídeos baseados nos textos de Sagan e Cortella, os conteúdos de Astronomia, as ideias dos Filósofos e principalmente a conceituação, como citado anteriormente, pois puderam desenvolver a própria concepção do eu-no-mundo, do ser humano enquanto existência e essência. Dentro da ideia de fazer Filosofia, procurou-se que o aluno partisse de 
um ponto inicial e desenvolvesse uma visão mais crítica sobre a própria existência, à luz dos conteúdos trabalhados. O ponto de partida é individual e único, bem como o ponto de chegada. Em Filosofia talvez não exista um ponto de chegada, mas um novo ponto de partida, num processo cíclico de criação de conceitos e revisão destes. Foi possível constatar pelo trabalho realizado que os alunos conseguiram fazer um percurso e agora possuem as ferramentas necessárias para continuarem este caminhar, refletindo sobre a sua existência e com interesses pelo Universo e pelas novas descobertas que a ciência proporciona.

Outra análise possível foi a realização do comparativo entre respostas dos alunos, considerando o questionário inicial e final tendo em vista os conteúdos de astronomia.

No que se refere à origem do Universo, foram analisadas as respostas dos alunos às seguintes perguntas:

Questionário Inicial: 2) Como o Universo se originou? Qual a sua estrutura?

Questionário Final: 4) Qual a origem de todas as coisas na natureza? 5) Como o Universo se originou?

As respostas dos alunos foram simplificadas simbolicamente no Quadro 2 a seguir:

Quadro 2 - Respostas dos alunos para as questões (q.2 do QI, q.4 e q.5 do QF) sobre a origem do Universo. BB: Big Bang; A: Arché; D: Deus; R: Grandes em virtude da razão; BB+: Big Bang detalhado.

\begin{tabular}{|c|c|c|c|}
\hline \multirow{2}{*}{ Aluno } & QI & \multicolumn{2}{|c|}{ QF } \\
\cline { 2 - 4 } & Questão 2 & Questão 4 & Questão5 \\
\hline A1 & BB & BB A & BB+ \\
\hline A2 & BB & A D & BB + \\
\hline A3 & BB & BB D & BB + \\
\hline A4 & BB & BB D & BB+ \\
\hline A5 & BB & R D A & BB+ \\
\hline A6 & BB & D & D \\
\hline A7 & BB & A & BB + \\
\hline A8 & BB & D & BB + \\
\hline A9 & BB & D & BB + \\
\hline A10 & BB & BB D & BB + \\
\hline A11 & BB & D & BB + \\
\hline A12 & BB & A & BB + \\
\hline
\end{tabular}

Fonte: Autores (2017).

Em relação à questão 2 do Questionário Inicial, nota-se nesta amostra de alunos que todos responderam com Big Bang (BB). No Questionário Final, na questão 4, 9 alunos mencionam Deus (D), 4 citam novamente o Big Bang, 4 mencionam Arché (A) e apenas um menciona a grandeza do homem em virtude da razão (R). Na questão 5, com exceção de um aluno, todos mencionaram o Big Bang com mais informações ( $\mathrm{BB}+$ ). Assim, verificamos que os alunos já possuíam uma concepção prévia sobre a teoria da origem do Universo, seja por senso comum, seja porque em algum momento tiveram contato com o tema nas disciplinas 
anteriores. Depois, com o conteúdo de Astronomia, verificamos uma ampliação do conteúdo exposto por eles, além de representarem também a teoria da Arché e refletirem sobre a existência de Deus. Constatamos assim a evolução conceitual dos alunos a partir do trabalho apresentado. Conseguimos conceber a conceituação proposta por Gallo, pois partiram de uma ideia inicial e desenvolveram um novo conceito, melhorando inclusive o existente, sobre a teorização da criação do Universo.

No que tange à composição do Universo e à condição da vida aqui na Terra, as perguntas analisadas foram:

Questionário Inicial: 3) Quais são os astros/estruturas/elementos que compõem o Universo? Como isso condiciona a composição da Terra e da vida aqui? Quais seus tamanhos e distâncias?

Questionário Final: 7) Quais são os astros que compõem o Universo? Quais suas distâncias e tamanho? Como isso condiciona a composição da Terra e da vida aqui?

Da mesma forma que o anterior, segue simbolicamente no Quadro 3 a síntese das respostas dos alunos.

Quadro 3 - Respostas dos alunos para as questões (q.3 do QI eq.7 do QF) sobre a composição do Universo e condição na vida na Terra. U: Composição do Universo; A: Arché; U+: Composição do Universo com mais detalhes; H: Hannah Arendt; p: Pequenos perante a natureza; BIO: Existência Biológica; P: Pascal.

\begin{tabular}{|c|c|c|}
\hline \multirow{2}{*}{ Aluno } & QI & QF \\
\cline { 2 - 3 } & Questão 3 & Questão 7 \\
\hline A1 & $\mathrm{U}$ & $\mathrm{U}+\mathrm{H}$ \\
\hline $\mathbf{A 2}$ & $\mathrm{U}$ & $\mathrm{U}+\mathrm{p}$ \\
\hline $\mathbf{A 3}$ & $\mathrm{U}$ & $\mathrm{U}+$ \\
\hline $\mathbf{A 4}$ & $\mathrm{U}$ & $\mathrm{U}+\mathrm{p}$ \\
\hline $\mathbf{A 5}$ & $\mathrm{U}$ & $\mathrm{U}+\mathrm{p}$ \\
\hline $\mathbf{A 6}$ & $\mathrm{U}$ & $\mathrm{U}+\mathrm{BIO}$ \\
\hline A7 & $\mathrm{U}$ & $\mathrm{U}+\mathrm{BIO}$ \\
\hline A8 & $\mathrm{U}$ & $\mathrm{U}+\mathrm{p}$ \\
\hline A9 & $\mathrm{U}$ & $\mathrm{U}+\mathrm{BIO}$ \\
\hline A10 & $\mathrm{U}$ & $\mathrm{U}+\mathrm{P}$ \\
\hline A11 & $\mathrm{U}$ & $\mathrm{U}+\mathrm{BIO}$ \\
\hline A12 & $\mathrm{U}$ A & $\mathrm{U}+$ \\
\hline
\end{tabular}

Fonte: Autores (2017).

Na questão 3 do QI, foram unânimes em citar a composição do Universo sem grandes detalhes (U), sendo que apenas um aluno citou a Arché (A). Na questão 7 do QF, todos mencionaram com mais detalhes a composição do Universo (U+), 4 citaram a pequenez humana (p), 4 citaram a Existência Biológica, um menciona Hannah Arendt $(\mathrm{H})$ e outro menciona Pascal (P). Novamente é possível verificar a evolução conceitual dos alunos. Partiram de uma concepção mais estanque do Universo para uma visão mais filosófica, refletindo sobre a nossa condição enquanto seres humanos. 
Como última análise, verifica-se nas questões a seguir a posição da Terra e do ser humano.

Questionário Inicial: 5) Qual a posição da Terra e do ser humano nesta estrutura? O que você pensa sobre isto?

Questionário Final: 8) Qual a posição da Terra e do ser humano nesta estrutura? 9) O que você pensa sobre isto?

Utilizando a mesma representação anterior, as respostas foram assim resumidas no Quadro 4:

Quadro 4 - Respostas dos alunos para as questões (q.3 do QI, q.8 e q.9 do QF) sobre a posição da Terra e do ser humano. U: Composição do Universo; PF: Posição Física; N: Não respondeu; U+: Composição do Universo com mais detalhes; p: Pequenos perante a natureza; R: Grandes em virtude da razão; BIO: Existência Biológica.

\begin{tabular}{|c|c|c|}
\hline \multirow{2}{*}{ Aluno } & QI & QF \\
\cline { 2 - 3 } & Questão 5 & Questões 8 / 9 \\
\hline A1 & $\mathrm{U}$ & $\mathrm{U}+\mathrm{PF} \mathrm{p} \mathrm{R}$ \\
\hline $\mathbf{A 2}$ & $\mathrm{U}$ & $\mathrm{U}+$ \\
\hline A3 & $\mathrm{U}$ & $\mathrm{p} \mathrm{R}$ \\
\hline $\mathbf{A 4}$ & $\mathrm{PF}$ & $\mathrm{PF} \mathrm{p} \mathrm{R}$ \\
\hline A5 & $\mathrm{U}$ & $\mathrm{p} \mathrm{R}$ \\
\hline A6 & $\mathrm{N}$ & $\mathrm{p} \mathrm{R}$ \\
\hline A7 & $\mathrm{N}$ & $\mathrm{N}$ \\
\hline A8 & $\mathrm{N}$ & $\mathrm{p} \mathrm{R}$ \\
\hline A9 & $\mathrm{U}$ PF & $\mathrm{p} \mathrm{R}$ \\
\hline A10 & $\mathrm{U}$ & $\mathrm{p} \mathrm{R}$ \\
\hline A11 & $\mathrm{N}$ & $\mathrm{U}+\mathrm{PF} \mathrm{p} \mathrm{R}$ BIO \\
\hline A12 & $\mathrm{U}$ & $\mathrm{BIO}$ \\
\hline
\end{tabular}

Fonte: Autores (2017).

Na questão 5 do QI, apenas 8 alunos responderam. A composição do Universo foi mencionada sem grandes detalhes $(U)$, por 7 alunos e outros dois mencionaram a posição da Terra como o terceiro planeta em ordem de distância ao Sol (PF). Nesta questão, nenhum deles desenvolveu a temática do ser humano e 4 alunos não responderam $(\mathrm{N})$. Já nas questões 8 e 9 do QF, nota-se apenas três citações da posição da Terra (PF) e complementam com a pequenez humana (p) e a grandeza do Homem (R). Os demais alunos abordaram a temática de forma mais humanística, trabalhando os aspectos dos filósofos, em especial a pequenez e a grandeza. A composição do Universo com mais detalhes (U+) foi também identificada nas respostas de três alunos. Também se identifica a retomada do conceito de dependência biológica da vida na Terra (BIO) em duas respostas.

Verificou-se assim que, partindo de uma visão apenas física do Universo, eles conseguiram no decorrer do trabalho desenvolver uma consciência mais crítica sobre a existência humana, refletindo de forma especial sobre a pequenez e a grandeza humana. 


\section{CONCLUSÕES E IMPLICAÇÕES}

$\mathrm{O}$ artigo apresentou os resultados da pesquisa que realizou uma proposta de trabalho docente que indicou um caminhar discente para pensar a existência humana, considerando conceitos de Filosofia e Astronomia. Identificou-se a proximidade destas duas áreas no conhecimento, no que tange a uma proposta para ser aplicada no Ensino Médio. Tal aplicação propiciou um caminhar discente à uma consciência crítica sobre si. Verificou-se que o uso de reflexões sobre o Universo no contexto da Filosofia auxilia a criação desta consciência crítica da própria existência. A intangibilidade da Filosofia foi facilitada pela concretude dos conteúdos da Astronomia. A busca sobre nossa origem foi ponto ímpar para esta avaliação crítica. O arcabouço teórico utilizado, dentre eles os PCN, indicam a Filosofia como uma disciplina para apresentação e realização de uma reflexão crítica. Os alunos, no decorrer das aulas, conseguiram realizar este processo filosófico e de conceituação do ser.

Mais especificamente, no que diz respeito à área de pesquisa em Educação em Ciências, considera-se um estudo original no que se refere às relações entre Astronomia e Filosofia, visando à interdisciplinaridade e à aquisição de conhecimentos dos alunos sobre as duas áreas.

As habilidades e competências propostas nos PCN (BRASIL, 1999) foram trabalhadas de forma eficaz. Ficou constatado que os alunos passaram pelas três etapas: Representação e Comunicação, Investigação e Compreensão, Contextualização sociocultural. Da mesma forma também foi utilizado os métodos didático-pedagógicos sugeridos por Souza (1995) sendo eles: Exposição, Interrogação, Exposição dialogada e Leitura e análise de textos. Assim, pode-se inferir que a pesquisa e o trabalho neste artigo descrito levaram a análises sobre o Universo no processo de ensino e reflexão filosófica e teve um caráter de sensibilização e criação da problemática existencialista apresentada. Além disso, também foi possível abordar a criação de conceitos, conforme Gallo (2006), por meio dos quatro passos didáticos: sensibilização, problematização, investigação e conceituação.

Tornar a Filosofia algo tangível foi possível considerando o estudo da Astronomia. Identifica-se que ambas as áreas (Astronomia e Filosofia) têm sua raiz comum: analisar a origem das coisas. No itinerário percorrido, pensar sobre o ser humano, quem somos, qual nossa participação nesta imensidão cósmica foi realizada e é relevante para o pensamento crítico do aluno. Estes partiram de um conceito simplista sobre o Universo e a própria existência, para uma conceituação mais bem elaborada. A partir do abordado nas aulas sobre Astronomia, os alunos conseguiram melhor expressar a concepção do Universo, sua composição, tamanhos e distâncias e evidenciaram aquisição de tais conteúdos. 
No que se refere à Filosofia, os conceitos dos filósofos trabalhados foram, de certa forma, apreendidos e ressignificados por eles, mais especificamente pelas obras dos filósofos Pascal, Heidegger, Sartre e Arendt, gerando uma ponte entre as duas áreas do conhecimento.

O desenvolver de um instrumento para trabalhar com alunos conteúdos de Astronomia, porém refletindo sobre indagações filosóficas foi alcançado. Com o trabalho os alunos tiveram contato com os conceitos específicos, assim, puderam melhor elaborar e refletir, evoluindo conceitualmente de acordo com o que foi proposto neste trabalho.

O presente trabalho teve como objetivo apresentar uma proposta de metodologia, aplicá-la e estudá-la com alunos do Ensino Médio. Tal intento, mesmo que de modo inicial, foi alcançado. Espera-se que o mesmo sirva de instrumento e/ou inspiração para outros docentes desenvolver a prática interdisciplinar junto aos seus alunos.

Para a continuidade deste trabalho vislumbra-se a possibilidade de novos estudos de preparar um material didático com maior densidade teórica e propostas outras de intervenção, servindo assim de referencial para aguçar novas propostas metodológicas e novos caminhos para o fazer docente.

Vale destacar que o trabalho docente, de forma singular no ensino público, possui entraves dos mais variados. Podemos elencar a preconcepção da inviabilidade de um trabalho interdisciplinar. Este fato pode ser justificado pelo pouco desenvolvimento crítico dos alunos no decorrer de sua formação inicial. Na outra esteira temos a pouca tradição na articulação entre docentes de disciplinas diferentes para um trabalho conjunto em uma mesma turma.

No ambiente escolar por vezes vivencia-se realidades difíceis, como aquele aluno que frequenta a escola em virtude da possibilidade de se alimentar, considerando que muitas famílias estão em condições precárias de subsistência. Realidades outras como a violência, drogas, famílias desestruturadas emocionalmente são também realidades existentes. Todo este contexto certamente dificulta o processo de ensino e aprendizagem, considerando a disposição do aluno, frente a condição social que se encontra. Todavia, como docentes é importante a manutenção da esperança, mesmo tendo de enfrentar obstáculos que fogem aos muros escolares.

A ideia de que não é possível fazer diferente, que as condições educacionais, principalmente no contexto público, não possibilitam tal ação, deve deixar de ser um preconceito de nós, docentes. Não se pretende criar um manual de como fazer, mas sim demonstrar aos docentes de todas as áreas do saber e, neste caso, de Filosofia, que é possível tornar os alunos mais interessados pelas aulas e conteúdos e que o "mesclar" de ciências torna a aula mais atrativa e eficiente. Neste caso, isto ocorre com o objetivo, por exemplo, de desenvolver o conhecimento de Astronomia e fazer com que os alunos sejam mais críticos em 
relação à própria existência. Uma proposta pela qual é possível mudar a realidade nas salas de aula.

As possíveis contribuições para o ensino são o estudo e a elaboração de metodologias conceitualmente adequadas e eficazes de ensino para alunos do Ensino Médio, bem como o compartilhamento desse estudo com professores. Além disso, essa soma de ações visualiza uma maior aproximação entre os conhecimentos produzidos academicamente sobre a temática do ensino de Astronomia na Filosofia, a partir da sua própria realidade.

Portanto, como este estudo, tais pesquisas podem contribuir para outras ainda a serem desenvolvidas nesta área interdisciplinar ainda pouco praticada e estudada.

Assim, refletir sobre a existência humana pode, de certa forma, contribuir para a formação de cidadãos críticos, conscientes de seu protagonismo social e político, preocupados em transformar suas realidades para um futuro melhor.

\section{REFERÊNCIAS BIBLIOGRÁFICAS}

ARANHA, M. L. A.; MARTINS, M. H. P. Filosofando: Introdução à Filosofia. São Paulo: Moderna, 2009.

ARANHA, M. L. A.; MARTINS, M. H. P. Temas de Filosofia. São Paulo: Moderna, 1998.

ARENDT, H. A condição Humana. Rio de Janeiro: Forense Universitária, 2015.

BARBOSA, C. L. de A. Didática e Filosofia no Ensino Médio: um diálogo possível. Educação Unisinos: São Leopoldo, 2008.

BARDIN, Laurence. Análise de Conteúdo. Lisboa: Edições 70, 2011.

BRASIL. Ministério da Educação. Parâmetros Curriculares Nacionais para o Ensino Médio. Brasília: Secretaria de Educação Média e Tecnológica (Semtec/MEC), 1999.

BRETONES, P. S.; JAFELICE, L. C.; HORVATH, J. E. Ten Years Of Latin-American Journal Of Astronomy Education RELEA: Achievements And Challenges For International Astronomy Education Development. Journal of Astronomy \& Earth Sciences Education (JAESE), v. 3, p. 110-124, 2016.

BRETONES, P. S.; MEGID NETO, J. An Analysis of Papers on Astronomy Education in Proceedings of IAU Meetings from 1988 to 2006. Astronomy Education Review, v. 10, n. $1,2011$.

BRETONES, P. S.; MEGID NETO, J. Tendências de Teses e Dissertações sobre Educação em Astronomia no Brasil. Boletim da Sociedade Astronômica Brasileira, v. 24, n.2, p. 3543, 2005.

BUSSI, B.; BRETONES, P. S. Educação em Astronomia nos Trabalhos dos ENPECs de 1997 a 2011. In: Encontro Nacional de Pesquisa em Educação em Ciências, 9., 2013, Águas de Lindóia. Atas... Rio de Janeiro; ABRAPEC, 2013. 
trabalhos apresentados nas reuniões anuais da SAB entre 1993 e 2003. In: XXX Reunião Anual da SAB, 2004. Boletim da Sociedade Astronômica Brasileira. São Paulo: USP, 2004. v. 24, p. 79.

CORTELLA, M. S. Qual é a sua obra?: inquietações propositivas sobre gestão, liderança e ética. Rio de Janeiro: Vozes, 2015.

FERNANDES, G. B. C. Uma abordagem humanística para o ensino de astronomia no nível médio. In: L. C. JAFELICE (Org.). Astronomia, educação e cultura: abordagens transdisciplinares para os vários níveis de ensino. Natal: Ed.UFRN, 2010. Capítulo 2, p. 89145 .

FERNANDES, T. C. D.; NARDI, R. Uma análise dos trabalhos sobre Educação em Astronomia nos Encontros Nacionais de Pesquisa em Educação em Ciências. In: Encontro Nacional de Pesquisa em Educação em Ciências - X ENPEC. Atas... Águas de Lindóia, SP, 2015.

GALLO, S. A Filosofia e seu ensino: conceito e transversalidade. Éthica. Rio de Janeiro, v. 13. n. 1, p. 17-35, 2006.

HEIDEGGER, M. Ser e Tempo: Parte II. Petrópolis: Editora Vozes, 2005.

IACHEL, G.; NARDI, R. Algumas tendências das publicações relacionadas à Astronomia em periódicos brasileiros de ensino de física nas últimas décadas. Rev. Ensaio. Belo Horizonte, v. 12, n. 2, p. 225-238, mai-ago, 2010.

LELLIOTT, A.; ROLLNICK, M. Big ideas: A review of astronomy education research 1974-2008. International Journal of Science Education. v. 32, n. 13, p. 1771-1799, Set. 2010.

MARRONE JÚNIOR, J.; TREVISAN, R. H. Um perfil da pesquisa em ensino de Astronomia no Brasil a partir da análise de periódicos de ensino de Ciências. Caderno Brasileiro de Ensino de Física, v. 26, n. 3, p. 547-574, dez. 2009.

MEDEIROS, L. Â. L. de. Cosmoeducação: uma abordagem transdisciplinar no ensino de astronomia. In: L. C. JAFELICE (Org.). Astronomia, educação e cultura: abordagens transdisciplinares para os vários níveis de ensino. Natal: Ed. UFRN, 2010. Capítulo 3, p. 147212.

NASCIMENTO. C. A. A construção de conceitos sobre a pequenez humana: Astronomia em aulas de Filosofia no Ensino Médio. 110 f. Dissertação de Mestrado em Educação. Universidade Federal de São Carlos, São Carlos, 2017.

NIELSEN NETO, H. (Org.). O ensino de Filosofia no $2^{\circ}$ Grau. São Paulo: Sofia SEAF, 1986.

ORTELAN, G.; BRETONES, P. S. Educação em Astronomia nos trabalhos das Reuniões Anuais da SAB entre 2004 e 2010. In: XXXVII Reunião Anual da Sociedade Astronômica Brasileira, 2012, Resumos... Águas de Lindóia., 2012. p. 76-76.

OS PARALAMAS DO SUCESSO. Tendo a Lua. São Paulo: EMI, 1991.

PASCAL, B. Pensamentos. Coleção os pensadores. Vol. XVI. São Paulo: Ed. Abril, 1973.

REALE, G., ANTISERI, D. História da Filosofia. v2 e v3. São Paulo: Paulus, 1990. 
SAGAN, C. Pálido ponto azul. São Paulo: Companhia das Letras, 1996.

SÃO PAULO. Secretária da Educação. Currículo do Estado de São Paulo: Ciências

Humanas e suas tecnologias. São Paulo: SE, 2011.

SARTRE, J.-P. O Ser e o Nada. Rio de Janeiro: Vozes, 2015.

SOUZA, S. M. R. Um outro olhar: Filosofia. São Paulo: FTD, 1995.

\section{ANEXO A}

Questionário Inicial

1) Qual a origem do nosso universo e qual o primeiro evento considerado pelos cientistas como o que deu origem aos Cosmos? Conseguiria explicar como ele ocorreu?

2) Como o Universo se originou? Qual a sua estrutura?

3) Quais são os astros/estruturas/elementos que compõem o Universo? Como isso condiciona a composição da Terra e da vida aqui? Quais seus tamanhos e distâncias?

4) As estrelas são formadas por estruturas químicas presentes em muitas coisas. Você saberia informar do que são compostas e o que elas proporcionaram com a evolução do Universo?

5) Qual a posição da Terra e do ser humano nesta estrutura? O que você pensa sobre isto?

6) Desde os primórdios o Homem, na sua busca filosófica, procura respostas para suas indagações mais fundamentais. Quais respostas você daria para as seguintes perguntas:

Qual a origem de todas as coisas?

De onde viemos?

Quem somos nós? Quem sou eu?

Para onde vamos?

Questionário Final

1) Você tem o hábito de olhar para o céu? Sim ( ) Não ( )

2) Frequentemente ( ) às vezes ( ) raramente ( ) nunca ( )

3) O que você pensa ou sente ao olhar para o céu?

4) Qual a origem de todas as coisas na natureza?

5) Como o Universo se originou?

6) Qual é a estrutura do Universo a partir da Terra?

7) Quais são os astros que compõem o Universo? Quais são suas distâncias e tamanhos? Como isto condiciona a composição da Terra e da vida aqui?

8) Qual a posição da Terra e do ser humano nesta estrutura? 
9) O que você pensa sobre isto?

10) Desde os primórdios o Homem, na sua busca filosófica, procura respostas para suas indagações mais fundamentais. Quais respostas você daria para as seguintes perguntas:

O que é o ser humano?

Existe uma natureza humana? Como você a definiria?

Qual o sentido da existência humana?

Somos seres livres ou predeterminados?

\title{
SOBRE OS AUTORES
}

\begin{abstract}
AUTOR 1.
Possui graduação em Administração de Empresas pela Universidade de Ribeirão Preto (2006), graduação em Filosofia pelo centro Universitário Claretiano (2012), mestrado em Educação pela Universidade de São Carlos (2017), graduação em Matemática pela Universidade de Franca (2017), graduação em História pela Universidade de Franca (2019) e graduação em Geografia pela Universidade de Franca (2020). Atualmente é professor de Filosofia e Coordenador Pedagógico na Área de Ciências Humanas e Sociais Aplicadas na Secretaria da Educação do Estado de São Paulo. Foi o pesquisador do estudo apresentado.
\end{abstract}

\section{AUTOR 2.}

Possui graduação em Química pela Universidade Estadual de Campinas (1991), mestrado em Geociências pela Universidade Estadual de Campinas (1999) e doutorado em Ensino e História de Ciências da Terra pela Universidade Estadual de Campinas (2006) em temas relacionados à Educação em Astronomia. Atualmente é Professor Associado da Universidade Federal de São Carlos. Foi o orientador da pesquisa. 